\title{
Periphery theorising for a truly internationalised discipline: spinning IR theory out of Anatolia
}

\author{
ERSEL AYDINLI AND JULIE MATHEWS
}

\begin{abstract}
Concerns over inequalities that have been located between the roles of the core and periphery within the development of the IR discipline have led to questions of whether it is possible to build up theoretical concepts in IR based on national differences. There have not yet been studies however providing an in-depth look at how IR theorising has been developing within a periphery country or region, and exploring both the local and core level factors inhibiting the development of original theoretical paradigms from within that context. By looking at the Turkish experience, the article postulates that homegrown theorising may be the only means for periphery IR to be respectfully acknowledged by the core IR discipline.
\end{abstract}

\section{Introduction}

The relationship between and the respective roles of the core and periphery in the development of international relations (IR) as an academic discipline have been the focus of discussion for more than a quarter century. For the most part this discussion has concluded that the core - and in particular, the United States dominated the discipline's birth and early growth, ${ }^{1}$ but that in more recent years IR has begun to live up to its name, showing rapid expansion outside of North America. ${ }^{2}$ It has also been noted however, that this expansion is in critical ways still limited. In terms of publications, leading IR journals still tend to publish the works of scholars from primarily North America or Western Europe, ${ }^{3}$ and the

${ }^{1}$ H. Alker and T. Biersteker, 'The Dialectics of World Order: Notes for a Future Archeologist of International Savoir Faire', International Studies Quarterly, 28 (1984), pp. 121-42; S. Hoffmann, 'An American Social Science: International Relations', Daedalus, 106 (1977), pp. 41-60; F. Neal and B. Hamlett, The Never-Never Land of International Relations, International Studies Quarterly, 13 (1969), pp. 281-305.

2 M. Kahler, 'International Relations: Still an American Science?', L. Miller and M. H. Smith (eds), Ideas and Ideals: Essays on Politics in Honor of Stanley Hoffmann (Boulder, CO: Westview), pp. 395-414; N. Palmer, 'The Study of International Relations in the United States', International Studies Quarterly, 24 (1980), pp. 343-64.

${ }^{3}$ E. Aydinli and J. Mathews, 'Are the Core and Periphery Irreconcilable? The Curious World of Publishing in IR', International Studies Perspectives, 1 (2000), K. Goldmann, 'Im Westen Nichts Neues: Seven International Relations Journals in 1972 and 1992', European Journal of International Relations, 1 (1995), pp. 245-60; S. Hajjar et al., 'The Literature of Political Science: Professional Journals in Four Nations', International Social Science Journal, 29 (1977), pp. 245-332; D. Pfotenhauer, 'Conceptions of Political Science in Western Germany and the United States', Journal of Politics, 34 (1972), pp. 554-91. 
most influential scholars working in the field, as selected by their peers, are mostly American. ${ }^{4}$

Underlying these findings, perhaps, is the argument that IR's expansion has been especially unbalanced in terms of the construction and spread of disciplinary knowledge. It was pointed out more than 20 years ago that the spread of ideas in IR was moving exclusively from core to periphery, ${ }^{5}$ and little seems to have changed since then. ${ }^{6}$ Herein lies the dilemma for IR as a truly global discipline, for no matter how many IR departments are opened up in universities worldwide, what really matters is whether the fundamental ideas investigated and taught within those departments are the exclusive products of a limited number of scholars. In other words, whoever creates the theories, controls the agenda. As long as the periphery is only on the receiving end of this division of labour, it will remain a weak, subservient partner in the discipline, and this imbalance will continue to limit the extent to which the discipline can achieve its goal of understanding global politics.

These concerns have led in recent years to discussion about the development of disciplinary ideas, and whether it is possible to build up theoretical concepts in IR based on national differences. ${ }^{7}$ While the questions are starting to be asked, there have not yet been studies providing an in-depth look at how IR theorising has developed within a periphery country or region, and exploring both the local and core level factors inhibiting the development of original theoretical ideas within that context. ${ }^{8}$ This article focuses therefore on the case of Turkey, a country with a long-established IR discipline, English-medium instruction in its major universities,

${ }^{4}$ S. Peterson, and M. J. Tierney, 'Teaching and Research Practices, Views on the Discipline and Policy Attitudes of International Relations Faculty at US Colleges and Universities'. Unpublished survey, available at: 〈http://www.wm.edu/irtheoryandpractice/trip/surveyreport05-06.pdf $\rangle$.

5 K. J. Holsti, The Dividing Discipline: Hegemony and Diversity in International Theory (Boston: Allen and Unwin, 1985).

${ }^{6}$ M. Ayoob, 'Inequality and Theorizing in International Relations: The Case for Subaltern Realism', International Studies Review, 4 (2002); Robert Crawford and Darryl Jarvis (eds), International Relations - Still an American Social Science: Towards Diversity in International Thought (Albany, NY: SUNY Press, 2001); S. Smith, 'The US and the Discipline of International Relations:

'Hegemonic Country, Hegemonic Discipline", International Studies Review, 4 (2002); S. Strange, 'Presidential Address: ISA as a Microcosm', International Studies Quarterly, 39 (1995), pp. 289-95; O. Waever, 'The Sociology of a Not So International Discipline: American and European

Developments in International Relations', International Organization, 52 (1998), pp. 687-727.

7 Much of this recent work has come out of China (for example, W. A. Callahan, 'China and the Globalisation of IR Theory: Discussion of 'Building International Relations Theory with Chinese Characteristics', Journal of Contemporary China, 10 (2001); D. C. Kang, 'Getting Asia Wrong: The Need for New Analytical Frameworks', International Security, 27 (2003), pp. 57-85; Y. Wang, 'On National Identity of International Relations Theories', Paper presented at the annual meeting of the International Studies Association, Montreal (2004). The effort raises important questions regarding what is meant by 'Chinese IR' or 'Turkish IR'. In this article 'Turkish IR' or the 'Turkish IR community' refers to Turkish citizens working in Turkish universities. It could also include foreigners working in IR departments in Turkey who have a highly internalised interest and understanding of local values, research attitudes, and even the language, but this is at present a very small group, if it exists at all. Similarly, Turkish IR scholars living and working for an extended period abroad may be considered as part of 'Turkish IR', but are more likely to have become a part of the local IR disciplinary community in which they are located.

8 Many attempts at peripheral theorising have met with exclusionary attitudes from the core. If we look for example at Gramscian based subaltern voices, we realise that as long as they remain non-conformist, they do not get embraced by the core (see the discussions that emerged from the series of talks on 'Subaltern Voices: Speaking and Theorizing from the Disciplinary Margins', University of Alberta, September 2006-March 2007 available via: 〈http://www.uofaweb.ualberta.ca/ polisci/SpeakersSeries_0607.cfm $\rangle$ ). Even those peripheral attempts that can be considered fairly 'assimilated' in the sense of accepting primary concepts of core IR theory, face exclusion. The best 
and on-going strong ties with core academia - both via foreign graduate study of Turkish academics (a practice dating from Ottoman times) and through active participation in foreign conferences. By looking at the Turkish case, this article tries to understand the factors contributing to a unidirectional movement of ideas within IR, and to the stubborn resistance of the IR discipline to true internationalisation of the discipline's theoretical underpinnings.

The international relations (IR) discipline has existed in Turkey for well over half a century, yet in many ways is still struggling to come together as a coordinated disciplinary community. Perhaps the most distinctive characteristic that emerges when trying to understand the discipline's development and current state is the complex and uncomfortable relationship it holds with the world of IR theory and theorising. Over the last 15-20 years in particular, 'theorizing' and the professional identities associated with how - and whether - one does it, have resulted in a divide in the local disciplinary community between 'theorists' (a title claimed by most) and 'others' (a title generally bestowed by 'theorists' on the rest). This divide splits along academic generations, educational backgrounds, professional interests, and socioeconomic classes, and is inextricably intertwined with a desperate competition for disciplinary power at the local level. Ironically, given the pivotal role that theory has come to play within the local discipline, it is in the realm of theory in particular that IR in Turkey has achieved the least. In this article we look at this inconsistency in Turkish IR by focusing in on the issue of IR theory-when and how it was introduced to the local disciplinary community, the factors surrounding its emergence as a privileged and therefore often claimed disciplinary activity, and the forms of scholarly activity that fall under the title of 'theorizing'. We end by considering the prospects for change in these established patterns and the implications these might have on broader core-periphery relations within the discipline.

To understand these issues we rely on the words of Turkish IR scholars - orally, as collected through interviews, ${ }^{9}$ and in writing, by looking at the texts that have been produced over the years by the local disciplinary community. We also draw on the personal experiences and observations of a group of scholars, and their attempts to build up a 'homegrown theory' study group in Turkey. ${ }^{10}$ The interviewees were selected to represent a broad picture of the local disciplinary community and thus ranged from newly appointed assistant professors to senior professors, employees of state universities and private ones, and scholars specialising in different fields, for example International Political Economy, security studies, and foreign policy. They also differed in gender and in geographic and socio-economic backgrounds. ${ }^{11}$ Due

example of this is perhaps Mohammed Ayoob's subaltern realism: 'Subaltern Realism: IR Theory Meets the Third World', in Stephanie G. Neuman (ed.), IR Theory and the Third World (New York: St. Martin's Press, 1998). Even this product of a core-educated, core-based 'peripheral' scholarship became the victim of 'inequality'. See the special issue discussion on this specific topic in International Studies Review, 4:3 (2002), and in particular Ayoob's own work in that volume,

'Inequality and Theorizing in IR: The Case for Subaltern Realism', pp. 27-48.

9 A series of interviews was carried out between 1999-2003 as part of one of the authors' unpublished Ph.D. dissertation and additional interviews were done by the authors in 2006 for this article specifically.

10 In late 2006, a small group of Turkish IR scholars gathered informally in Ankara for a brainstorming session in order to assess the need and potential parameters of locally based IR theorising in Turkey. The group is hoping to follow up with a larger meeting in 2007, possibly to contribute to an eventual 'Anatolian School of International Relations Theory'.

11 The number of Turkish IR scholars who have expressed or displayed a particular interest in theorising (either in their publications or by teaching IR theory) is very small. Through the various 
to the relatively small size of the IR disciplinary community in Turkey and the potential for easy identification of cited scholars, the interviewees' identities are kept anonymous in most cases.

In choosing to look at texts as a way of gaining insights into the workings of a particular community, such as an academic discipline, we drew on research done in the area of social-psychological functioning, for example Vygotsky and the neoVygotskian activity theorists, ${ }^{12}$ and further developed by the literary critic Mikhail Bakhtin. ${ }^{13}$ The formers' works attempt to understand relationships and interactions within a sphere of social activity by exploring the 'tools' or 'means' used by the participants. Bakhtin developed more fully the idea of written texts as comprising those means of social activity. A Vygotskian/Bakhtinian perspective views the agent of any action as inseparable from the means that s/he uses to 'mediate' a particular activity. So, like a blind person using a stick to navigate a path, an IR scholar uses written texts to navigate the disciplinary community. Take for example, the written discourse and genres of IR scholars; a Vygotskian/Bakhtinian approach allows us to operationalise what those texts mean in terms of core-periphery disciplinary relations, by suggesting various questions: What topics are being written about? What types of publications earn the greatest prestige? What types of gate-keepers (for example language restrictions, limited resources, less-than-blind review processes) exist to restrict some participants' access to means? We found that by seeking answers to these types of questions we were able to gain insights into the general priorities and power-relations within the local Turkish disciplinary community, and that by looking at individual IR scholars' choices in written discourse we could learn much about that person's aspirations, professional identity, and limitations both with respect to the peripheral (Turkish) community as well as to the core disciplinary community.

On a final methodological note, it is important to define first why and then how the terms 'core' and 'periphery' are used in this article. It is possible to compartmentalise the structure of the global IR discipline in different ways. One might argue for example, that there are horizontal disciplinary links according to methodological or theoretical orientations. The problem with such a horizontal approach to understanding the discipline is that even though there may be peripheral scholars sympathising or aligning their works with these theories or methods, as long as they are not a part of the production and dissemination of these particular areas of knowledge, they can not truly be counted as a part of them. A core-periphery framework offers the possibility to compartmentalise the discipline in a manner that addresses this problem. Having said that, the core-periphery distinction is not

means of data collection in this study, the opinions of a majority of these were able to be gathered. The arguments made in this article - and supported by relevant quotations - reflect what can therefore be considered as a majority perspective among Turkish IR scholars with an interest in theory.

12 L. S. Vygotsky (1978). Mind in society: The development of higher psychological processes, trans. M. Cole, V. John-Steiner, Sy. Scribner and El Souberman (Cambridge, MA: Harvard University Press). Examples of scholars in a neo-Vygotskian tradition include Y. Engestrom (1990). Learning, working, and imagining: twelve studies in activity theory (Helsinki: Orienta-Konsultit Oy; Leont'ev, A.N, 1981). The problem of activity in psychology, in The Concept of Activity in Soviet Psychology, ed. J. V. Wertsch (Armonk, NY: M.E. Sharpe).

13 Two primary collections of Bakhtin's works are of particular interest: Speech genres and other late essays, ed. Caryl Emerson and Michael Holquist, trans. Vern W. McGee (Austin, TX: University of Texas Press, 1986); and The Dialogic Imagination: Four Essays, ed. M. Holquist, trans. Kenneth Brostrom (Austin, TX: University of Texas Press, 1981). 
without its own complications. Most importantly, the terms have both geographical and non-geographical aspects. Within the core (which is sometimes called the 'West'), there are geographical divisions between the Anglo-Saxon world primarily (the core of the core) and the rest, for example, Western Europe (the periphery of the core), but there are also non-geographic distinctions between these two sub-groups, based on the degree to which theorists within the sub-group accept that theorising is contextual. Thus the core of the core does what they consider as 'context-free' theorising, while the periphery of the core does explicitly contextual theorising. Both groups however, have access to broad dissemination possibilities for their works. Turning to the periphery, we can speak of a 'core of the periphery', which has at least some technical and linguistic access to the core, and thus access-though imperfect - to broad dissemination possibilities. This group has the possibility of participating in IR theorising, of either type, though it is a challenge to disseminate it in privileged core venues. The periphery of the periphery, which may be even further separated from their colleagues by socio-economic factors, is essentially cut off from the core, lacks access to dissemination possibilities, and thus is unable to engage in any kind of broad level theoretical discussion.

\section{Mapping the state of IR in Turkey}

\section{Monopoly of the Mulkiye}

The foundations for IR in Turkey came out of Ankara University's Mulkiye Mektebi (School of Government) itself a carryover from higher education during the Ottoman times, that later came to be known as Siyasal Bilgiler Fakultesi (SBF, or Political Science Faculty). A distinct IR track within the school was eventually established in the 1950s, and produced its first Ph.D. student in 1956. The Mulkiye came to hold an incontrovertible monopoly over training and scholarship in the field of IR. Although a few other similar faculties existed, the prestigious Mulkiye was the only one that truly mattered, as its graduates alone were eligible for service in the foreign ministry. Small and exclusive, the Mulkiye became the world of the relative elite. A grooming ground for future diplomats, policymakers or policy advisors, the curriculum focused on diplomatic history and international law, and served a student body which, more often than not, was made up of the children of the country's wealthier families, often past diplomats and policymakers. ${ }^{14}$ These students were not only familiar with the world they were training to enter, but had the foreign living experience and often the language skills to ease their transition into the field. Professors in the field were often diplomatic historians or retired diplomats.

With the entire local IR disciplinary community essentially reduced to one department, whatever happened in that department had a huge impact on the local discipline. The retirement of certain faculty members, the firing of others, or the

14 This description is not unlike ones of IR in the US in the first half of the 20th century. A discipline dominated by 'enlightened men of learning and leisure', noted for unclear boundaries between academia and politics, and in which practitioners wrote for practitioners. William Wallace, 'Between Two Worlds: Think Tanks and Foreign Policy', in Christopher Hill and Pamela Beschoff (eds), Two Worlds of International Relations (London: Routledge, 1994), p. 140. 
particular politicisation of the Mulkiye students and faculty, had the potential to disrupt the overall progress of the local discipline. Major national events, such as political disruption within the country in the 1970s, or the coup of 1980 were all reflected in the department. When a significant percentage of the Mulkiye faculty were fired or sent to jail after the 1980 coup, it took nearly a decade for the department and thus the discipline - to recuperate and regroup. (Though, of course, one could equally argue that this huge upheaval actually helped the local IR community in that it finally allowed other departments to emerge from under the Mulkiye's shadow).

The Mulkiye excelled at producing well-informed policymakers and diplomats, but neither the school's Ottoman-age style of teaching and learning nor its primary curricular focus on policy was conducive to the development of theory and theorising, a criticism raised early on by a leading faculty member. ${ }^{15}$ Teaching and learning was based on discipline, memorisation, minimal external reading, taking vigilant notes from the professors' lectures and writing exams based on those lectures. This style did not accommodate critical engagement with the ideas being presented, nor did it promote reading diverse material and comparing and evaluating arguments, all of which are essential aspects to conceptual development. ${ }^{16}$ Rather than being questioned, the style remained largely unchanged over the years as those students who performed best in this system were taken on as graduate students and eventually faculty members. One could hardly expect theoretical breakthroughs to come out of such a context.

Moreover, the fact that the graduates of this leading department for IR in Turkey almost all went on to serve in the foreign ministry, meant that policy-relevant research was dominant in the Mulkiye, and thus in IR in Turkey - at the expense of theory. As is the case in most of the world, the policy community was not then, nor is it now necessarily sympathetic to theoretical works. Just last year, a retired Turkish diplomat speaking at a workshop on IR teaching and studying expressed his belief that 'theory and practice do not fit', and that theory does not 'provide solutions' to urgent problems. ${ }^{17}$ Unsurprisingly, when the Turkish Foreign Ministry sponsored Mulkiye faculty members to produce the first volume on Turkish Foreign Policy, a book that would constitute the primary textbook for generations of future IR students, they particularly demanded a descriptive, policy-relevant work, not theoretical abstractions. In its training and scholarship therefore, the IR community in Turkey was entirely focused on meeting the demands of daily foreign policy issues and foreign policymakers.

\section{Theory as balancing}

In the 1980s, the growth worldwide in the number of IR departments and students struck Turkey as well. Along with an overall opening up and political liberalisation

15 Suat Bilge, Politika Ogretimi Sympozyumu (Ankara: Sevinc Matbaasi, 1962).

${ }^{16}$ The style is referred to pointedly as the 'Mulkiye Ekol style of teaching' by Mustafa Aydin in the proceedings of the 2005 workshop on IR teaching in Turkey, Uluslararasi Iliskiler, 2:6 (2005). In recent years, discussion has begun to emerge proposing new and distinct approaches to studying and teaching in International Relations, a good example being A. Nuri Yurdusev's, International Relations and the Philosophy of History: A Civilization Approach (New York: Palgrave Macmillan, 2003).

17 Turhan Firhat, ibid, p. 72. 
of the country, the IR discipline saw not only a growth, but an increasing number of students from non-elite socioeconomic backgrounds joining international relations programs. With the influx of students there was a dividing of the student body between the majority elite and the small but growing minority of non-elite students - as noted in the words of some self-described 'non-elite' students of the era:

In the classroom you could always tell who was who because the aristocrat kids all sat together. There were only a few of us kids from poor backgrounds and we always sat together too...

I came from a family that was not rich ... I started out in IR to be a diplomat. To be a diplomat, a Turkish representative abroad, it is a very interesting and challenging task. But in the later stages, say, in the middle of my undergraduate education, I understood it was very difficult for us to enter the foreign ministry because of some, well, obstacles.

I soon realised it was practically impossible to become a diplomat because I only had weak German skills, and I didn't know French or English.

The divide between the elite and non-elite operated like a domestic core and periphery-with all of its accompanying restrictions. With the domestic 'core' dominating the discipline in foreign policy, the domestic 'periphery' faced a struggle, complicated by their lack of family connections and foreign language skills. As a weak but growing minority group that was gradually advancing up the ladder of the local disciplinary community, it is unsurprising that the domestic periphery students would seek new ways of proving themselves, new ways to compete, and new means to compete with - ways and means that were not within the exclusive control of the domestic core.

At about the same time - the mid-1980s and early 1990s - there was a push by the Turkish Ministry of Education and later by the Higher Education Council to send large numbers of students abroad for graduate studies. The peak of this effort was the 1993-1995 dispatching of more than 4,000 students. For the first time, masses of students from all backgrounds were able to go abroad for graduate studies.

For the student of international relations, studying in North America or Europe meant being exposed for the first time to the world of IR theory and in many cases to the understanding that producing theory was the highest role to achieve in the discipline. For the non-elite IR student returning to Turkey, 'theory' meant a new area in which they could compete and excel without family connections. Armed with Western knowledge, the domestic 'periphery' began using theory as a shield to balance against the domestic core and even to penetrate into the core itself.

Throughout the 1990s, we can see a growth in works of a generally theoretical nature being produced by Turkish IR scholars, as one scholar after another tried to show him or herself as more 'theory-driven' than the rest, or simply, as one IR scholar who was an assistant professor at the time says, 'to try and prove to people that they knew theory'. To draw an analogy with IR terminology, what we see in the 1990s is a grand scale literary attempt at balance of power. To balance against the older, larger, elite generation of IR scholars (and their traditional discourse of diplomacy, history, and international law), the younger, smaller, often non-elite products of the foreign study-abroad programmes began making use of the means of the Western IR community - the discourse, genres, and topics of IR theory.

There is no doubt whatsoever that they were successful in their goal of balancing against the local IR elite by introducing a new and powerful discourse to the Turkish disciplinary community. It is difficult to find an IR scholar in Turkey today who will 
not in some way attempt to explain how his or her works incorporate a theoretical perspective into their analyses. The prioritising of 'theory' has become so widely accepted that scholars of all backgrounds try to claim their position as theorists, but it is most noticeable among the generations of the late 1980s and afterwards. The phenomenon manifests itself vividly when you hear Turkish IR scholars say something along the lines of, 'yes, I write primarily about Turkey . . but I do it in a theoretical way'. The following excerpt from an interview with a scholar who completed his Ph.D. in England and returned to Turkey in the early and mid-1990s not only reveals the attempt to identify himself as part of the new, 'theoretical' community, but also to draw a generational line between himself and the past:

The scholars in Turkey before the 1990s focused on Turkish foreign policy issues, or some other empirical, national issues . . . case studies. Nowadays in Turkey I see that, like me, some other scholars have started to teach theories of IR. This should be taken as a positive contribution made by the new generation of IR scholars. Of course, still the majority of IR scholars in Turkey focus on issues which are concerned with Turkey or Turkish foreign policy ... this is normal, most of the time we are occupied by national problems and issues. Because of this I am very sad to say that I am one of those whose writings are concentrated on issues of Turkish foreign policy. But, what I try to do even I am studying and writing on these issues, I try to look at the problem in a theoretical perspective.

When speaking to those older generation members who were themselves educated abroad, the divide becomes less clear, and the overall theory issue takes on greater complexity. While most senior scholars generally recognise the importance of theorising both in the core and in the local IR community, they are sometimes more willing than the younger scholars to admit that they generally don't 'do theory'. One senior scholar dismisses one of her own works somewhat bitterly:

This is purely empirical and descriptive, a product of my own research. It has no link to a body of theoretical literature on the topic because I never had a chance to look at that literature. And I seriously doubt I will have a chance.

One of the very first Turkish scholars to go abroad and receive training in IR theory at a prestigious US institution in the late 1970s blames his admitted lack of theoretical works on time constraints and easier alternatives, and draws attention to a dilemma of the older generation's finest academic potential being drawn prematurely into leadership roles that prevented them from doing challenging, theoretical research:

When I returned to Turkey the discipline was so small here that I immediately became promoted and took on important administrative duties. This kept me extremely busy. I had to build up our department. It still keeps me busy. So when people come to me and ask, I write chapters for their books, usually concrete things on Turkey's relations with Europe, European politics, and so on. Since I don't have much time to publish, I like the work because easily then I can publish ... If I were able to work in my own tempo, I could probably have formed my own agenda more, looked for different publishing spaces, journals ... but I don't have the time and there is always the demand. I work according to that demand.

Still another senior scholar, one well respected and published internationally, carefully keeps the door open to the idea of his own works having at least a 'theoretical perspective', but dismisses overall the assertion of any actual 'theorising' being done in Turkey at all: 
As you know, I'm not doing theoretical work. Nobody's doing theoretical work in Turkey. I'm rather doing policy oriented work, but I use IR theories.

His statement raises the obvious question of what we mean when we speak of 'doing theory'. Do we mean 'using' IR theories? Do we mean - as implied in the previous quote - drawing a framework before analysing? Or do we mean something else?

\section{Categories of theory}

\section{'Pure' theorising}

The same professor who claimed that 'nobody' is doing theoretical work in Turkey, explained in this way what he meant by theoretical work:

Pure theoretical work, which is to be published in theory journals like International Organization, International Security, or International Studies Quarterly. Original theoretical work ... no work like that is being done here. Sure, there are some people doing some kind of theoretical work in Turkey, but they don't publish it in good journals. Most of it is published in Turkish and they are borrowed works. They repeat what the theory people are saying in the US. You see, they are translations.

His description of so-called pure theorising resembles others' efforts to distinguish types of theorising, in particular Lepgold's 'pure' theorising category, ${ }^{18}$ which specifies that the goal of such 'pure' or 'referent-free' theorising is to find coherent explanations for broad phenomena, while remaining unattached to specific areas. Such a definition would be questioned by some as unattainable. As one young Turkish IR scholar pointed out to us, 'You won't see an Alexander Wendt in Turkey because Wendt was writing from Wisconsin [sic]!' In other words, even if actual theory construction does take place in Turkey, it will not likely be the same as that carried out by core IR scholars. His point recalls Cox's well-known position that so-called 'pure' theorising is in any case affected by the contexts in which the theorist operates. ${ }^{19}$ The questions theorists choose to speculate on, the ways they choose to do so, and the interpretations they give to the answers they find, are all affected in multiple ways by the theorists' own backgrounds and the social worlds they interact with. This debate temporarily aside, any existing theoretical literature that does not explicitly address a particular country or region, can be considered for the moment 'pure' theorising.

\section{Homegrown theorising versus application and translation}

These are the words of a young Turkish scholar who spoke of her aspirations to produce original theory based on local contexts and questions:

18 Joseph Lepgold, 'Is Anyone Listening? International Relations Theory and the Problem of Policy Relevance', Political Science Quarterly, 113:1 (Spring, 1998).

19 R. W. Cox, 'Social Forces, States, and World Orders: Beyond International Relations Theory', Millenium: Journal of International Studies, 10 (1981). 
I would like to be someone who can combine theory and policy. I would like to first take the theories that the core produces and use them in my efforts to explain things in Turkey. But better yet, I would like to be someone who could not only explain things on a conceptual level, but also somehow build up some original perspective out of looking at Turkey's international relations or Turkey's experiences. That's my goal. I would call myself really successful if I could come up with a work identified as an original theoretical perspective originating out of these lands, out of Turkey or Turkey-like countries. That would certify that knowledge has accumulated in this country and finally produced something.

From this statement we can conceive of a second level of theorising, a 'homegrown' theorising in which entirely new patterns, understandings, frameworks of analysis are sought through the construction of theories stemming from 'local' experiences. These 'local' experiences do not mean simply the last century's history of the Turkish republic, nor does it mean that the resulting theoretical activity is relevant only to Turkey or her neighbours. Examples of 'local' Turkish contexts out of which theorising might come include contexts such as mid-size powers in global affairs, Islamic democracies, former Empires, democratising countries located in anarchic regions, or multicultural nations. These and many other categories describing aspects of Turkey's past and present could provide valuable starting points for original, homegrown theorising. Homegrown theorising may also involve existing theoretical questions or debates, but using local experiences, history, and contexts to locate gaps within and build onto those existing theories. Ultimately therefore, homegrown theorising refers here to theorising based on or incorporating contexts and experiences different from those that inform core-based theorising. The aim may be to theorise problems or issues that are locally significant (but not deemed worthy of interest to the IR core) or to modify and reform existing core-based theorising by drawing on local contexts and experiences. ${ }^{20}$

Following this level is a third, the one that most Turkish IR scholars seem to mean when they say they 'apply a theoretical framework'. This 'application level theorising' has various sub-categories of its own, but at its most basic seems to refer to leading off a written work with some kind of literature review, rather than jumping straight into a description of the particular event or issue. Application can also refer however to those scholars who take an existing theoretical model, and draw on the Turkish or regional experience to provide evidence of the model's usefulness as a way of looking at things. Thus, for example, a study using a constructivist approach to explain Turkey's relations with the EU is a form of application theorising. What distinguishes it from 'homegrown' theorising is not simply its reference to an existing body of theoretical literature however, but rather the solely confirmative use of that literature - offering your context as another ground for further confirmation of an imported concept. Homegrown theorising in contrast, may address an existing body of literature, but finds a gap or inconsistency in that literature and then adds to that existing literature with concepts derived out of the local context and case. ${ }^{21}$

20 These two aims have been referred to respectively as 'greenfield' and 'brownfield' theorisation. Tore Fougner, personal communication, 2007.

21 The works of leading Turkish IR theoretician Nuri Yurdusev serve as an example of the fine line between these two categories. While obviously reflecting application to some degree, his works and their critical engagement with the core theories-in particular the English School-clearly display as well homegrown elements. See for example N. Yurdusev, 'The Middle East Encounter with the Expansion of European International Society', in Barry Buzan and Ana Gonzalez-Pelaez (eds), 
An interesting example of how homegrown theorising might take place comes from balance of power theory. At a time when the prevailing Waltzian view was that countries balance against rising powers, Stephen Walt looked to the Middle East and alliance patterns there and wrote that in fact they balanced against the threat potential. ${ }^{22}$ The work received great attention and admiration, and quickly became part of the core theoretical literature. While legitimate questions can be raised as to whether such a reformation of an existing theory, coming from a local Middle Eastern scholar, would have been received with equal praise by the core, it would (at least hypothetically) have been a powerful example of homegrown theorising. The irony from this example is that at a time when most Middle Eastern 'theoreticians' were teaching and translating Waltzian balance of power theory, Waltz's own student was busily using the local neighbourhood to further the original theory.

Finally, there is a fourth level of theorising, implied by the earlier cited senior professor's reference to 'borrowed works'. In this case, someone writes a piece in Turkish that basically translates ideas or concepts that have already been expressed abroad. This 'translation level' theorising includes works that provide overviews of particular core theoretical paradigms or perspectives, translating them into Turkish to make them accessible to the average Turkish IR student. In this sense they represent more than simply translations, but rather a kind of review of the literature. This level also includes the major textbooks of IR, ${ }^{23}$ which present in Turkish major ideas from the Western disciplinary community.

By numbering these levels of theorising the intention is not to prioritise them in terms of value, though there is a logical progression in a disciplinary community of one building on the other. All levels are necessary and interdependent elements in the process of community-wide theory building. Translations are necessary to expose the broader disciplinary community, beyond those few who have access through language and study abroad experiences, to existing theoretical ideas. For example, as-yet-undeveloped theoretical ideas and concepts may be hidden in areas of Turkey where the very idea of 'IR theory' and its use is available only in translation. Such unexplored ideas and concepts could include theorising on trade and security in the Black Sea region, or concepts of religious coexistence from central Anatolia as can be found in the centuries-old writings on human-centric peace by Rumi. ${ }^{24}$ Such possibilities will go untapped unless existing theoretical ideas and concepts as well as core discourses and genres for disseminating those ideas are first made available through translations to the full IR disciplinary community in Turkey. Applications of existing theory are also necessary, both to add confirmations to those existing theories (of use to the larger disciplinary community) and to provide examples of and practice in the use of theory (of use to the local community).

International Society and the Middle East: English School Theory at the Regional Level, (Basingstoke: Palgrave-MacMillan, 2008).

22 Stephen M. Walt, The Origins of Alliances (Ithaca, NY: Cornell UP, 1987).

23 See for example Mehmet Gonlubol, Uluslararasi Politika: Ilkerler, Kavramlar, Kurumlar, 4th edn (Ankara: Attila Kitabevi, 1993); Faruz Sonmezoglu, Uluslararasi Politika ve Dis Politika Analizi, 3rd edn (Istanbul: Filiz Kitabevi, 2000); and Tayyar Ari, Uluslararasi Iliskiler Teorileri (Istanbul: Alfa Yayinlari, 2002).

24 Mawlana Jalal ad-Din Muhammad Balkhi (Rumi) was a 13th century Muslim poet, jurist, and theologian, who spent most of his life in central Anatolia. His importance is considered to transcend national and ethnic boundaries because of his emphasis on peach and harmony. 
Having said that all levels of IR theorising are important, the experience in Turkey over the last 15-20 years has shown instead that a hierarchical perspective is generally taken. There is the tendency for Turkish IR scholars to either deny the existence of or to put down others' theory efforts as less important than their own. Thus, scholars involved in translation of theory criticise those who do 'only' policy studies, scholars doing some form of application theorising tend to criticise the translators, and scholars who participate in homegrown theorising put down the application studies.

Confusing matters further, differing interpretations or misrepresentations of what may or may not constitute examples of certain levels become manipulated for purposes of building up professional identities or supporting professional rivalries. Scholars sometimes claim to conduct different levels of theorising than they actually do. In most cases there is just a general claim to 'theorising' but in others there is the implication that the scholar is conducting, for example, 'pure' theorising, when, according to our definition, their works would more likely fit under the heading of application studies. For example, a scholar claiming to be a 'theoretician' because s/he works on questions of strong state traditions in anarchic environments, but who explores this issue by using existing neoliberal concepts and frameworks to analyse the Turkish case, is doing application-level theorising.

Finally, there is the complex issue of those Turkish scholars - though very few in number-who participate entirely in existing core theoretical discussions at an abstract level, without any reference to Turkey. If these scholars are truly doing this without any connection to Turkey or to regional experiences, if they are in that sense, indistinguishable from their core colleagues in terms of the contribution they are making to that theoretical discussion, then in light of Cox's arguments that there can be no truly 'context-free' theorising, it would appear that such scholars have in fact been fully assimilated into the core disciplinary community, and no longer can really be categorised as 'periphery' scholars, even if geographically they are located in Turkey.

\section{In search of homegrown theorising}

There have been occasional examples of homegrown theorising in Turkey, but since most never get translated into English, it is worthwhile to look at a couple in detail in order to both clarify further the differences between homegrown and application theorising, as well as make clearer the potential value of homegrown theorising out of the periphery for IR theory in general. Two works that seem to represent interesting examples are Baskin Oran's Mid-Size Power Theory, which, though written in 2000, is a product of the older, Mulkiye generation of scholars, and Ahmet Davutoglu's Strategic Depth, which is the product of a scholar from the domestic periphery, who happens to also be the current primary foreign policy advisor to the Turkish Prime Minister and Foreign Minister.

Davutoglu's book opens by positioning itself firmly within a Western methodological framework of description, interpretation, explanation and prescription - an approach he says is best exemplified by Huntington's work on clashing civilisations. From there he breaks away from Western tradition and begins contributing at what we could call a 'homegrown' level. The focus of the book evolves around a 
developing world dilemma: the question of discrepancy of power between what might have been expected from a country based on their history, and what they have actually achieved in current global politics. Contrary to most practices in the modernising world, in which the past is generally ignored or presented as a liability, Davutoglu argues for bridging a country's historically accumulated values and influence with its current strategic assets, for example geography, economy, population, democratic system, in order to realise greater influence. In the Turkish case this is presented as a kind of democratic neo-Ottomanism.

Could Davutoglu's ideas be generalised beyond the Turkish case? It certainly seems possible. Many Islamic countries, for example, are struggling with a status inconsistency problem. Even the current violent Jihadist challenge can be traced back to this conflict since it reflects the frustration of countries and peoples with images of a glorious past, oftentimes combined with realities of modern wealth, but nevertheless failing to attain a pivotal position in global affairs. Whether or not Davutoglu's conceptualising of this phenomenon and his prescription of remaining loyal to one's past can provide solid responses to problems in the Middle East is of course open to question - but this rarely happens because of its limited Turkish audience. Were his ideas to be made available to a wider audience, were they to be thus open to discussion, debate and revision, it could only be a positive contribution to the overall disciplinary debate.

\section{A tale of two books}

For decades, IR teaching at the Mulkiye was completely dominated by one book: Olaylarla Turkis Dis Politikasi, or Turkish Foreign Policy Through Events. ${ }^{25}$ As described by one of the professors who for years used these edited volumes in his classroom, these were finely written works, but nonetheless works of collected chronological descriptions of Turkey's relations with other countries. The contents were determined according to needs of the books' sole funder (the Turkish Foreign Ministry) and by whoever existed in the department and could contribute a chapter on his/her expertise (and in such a small department the result was very small volumes) - not according to any overarching theme. By the mid to late 1990s it was painfully obvious that there was a need for a new book, one independent from the Foreign Ministry, and one that would be integrated and cohesive. This led members of the Mulkiye faculty to search for a thematic starting point for a new book. Methodologically, they conceived of a basic construct of international environment +internal dynamics = resulting foreign policy'. Everyone contributing to the new book would have to follow this structural pattern in their analysis, and the best people could be commissioned who could write accordingly. Simultaneously, there was also a search for a conceptual theme to tie the book's pieces together. The scholar who would ultimately edit the volume, Baskin Oran, decided to draw on an idea he had been reading about in a book by William Hale, ${ }^{26}$ which spoke about the actions of 'mid-sized powers'. The basic idea was that Turkey is a 'mid-sized'

\footnotetext{
25 The first edition of this was an unedited collection of works, the later 1970s version was slightly edited by Mehmet Gonlubol.

26 Turkish Foreign Policy: 1774-2000 (London: Frank Cass, 2000).
} 
international actor and that because of this, its actions in international politics - both what it can, and can not, do - are predictable. Once Oran and his colleagues adopted this concept to bind the book together, he says that most of the issues that they had been studying with respect to Turkish foreign policy, became much easier to understand:

Basically, this theory allowed me to locate the Turkish case in its rightful place. I realized that what we had been studying all those years was just the relations of the actor, but we had no idea of who the actor was and what it could or could not do. By starting with this mid-sized state theory, we were able to understand the major behavioral characteristics of the actor. We were finally able to go beyond a descriptive stage, into predictive and prescriptive stages. So many things said and written on, for example, Turkey's refusal to join with the U.S. in the invasion of Iraq, can be explained with this theory. A mid-sized state, regardless of its own inflated image of its own power, can't fully cooperate with the hegemon, because a mid-sized state still has the decision to make whether it's going to be a pivotal state or just an ordinary one. With this decision therefore, Turkey was saying, 'I am still the best candidate for being a pivotal state'.

But is this an example of homegrown theorising? Oran describes how he not only applied the existing theory, but also revised it by introducing what he noticed was a missing distinction between 'strategic' and 'non-strategic' mid-size actors. By looking at his own case he realised that the existing theory was still lacking a particular dimension. With this addition, he seems to have moved beyond application to homegrown theorising. Unfortunately of course, no one in the West would likely be aware of this contribution, since it was not published outside Turkey (though it is currently being updated, translated and published at the University of Utah).

\section{Still underachieving}

With the monopoly of the Mulkiye broken, and with the numbers of IR departments, students, and foreign-trained scholars skyrocketing in the last 15 years, why is it that we see only a booming of application-level theorising (and a domination in recent years of applications of critical theories and approaches)? Why is there still an underachievement of homegrown theorising?

\section{Periphery-based causes}

Perhaps the first reason for this underachievement is the fact that although talk of theorising has become commonplace, its use has not been for purely academic purposes. With theory being used as a 'balance of power' tool, its practice often remains elusive, ${ }^{27}$ unsubstantiated, and shallow. IR departments have seen cases of professors who have never undergone graduate-level exams in IR theory or perhaps never even taken a comprehensive, graduate-level IR theory class, becoming known as 'theorists' and being assigned the task of training future Turkish IR scholars in IR

27 It became clear during the 2007 homegrown theorising workshop that there were as many interpretations of what theory is, the need for homegrown theorising, and the ways to do it, as there were scholars. 
theory simply because they have come from abroad. In many cases, this results in teaching a very limited picture of IR theory - focusing on whatever theory(ies) the professor is familiar with, from selected epistemological and methodological approaches. Over the years this has led to the importation into IR in Turkey of waves of theories and approaches - whatever represents the cutting edge at the time of the professor's own foreign study experience. Students become exposed to a particular wave and remain unaware of the fuller spectrum of theories, concepts, and approaches. Such a pattern prevents any accumulation of debate over IR theory in Turkey as each successive generation dismisses or fails to recognise any value in the previous generation's efforts.

Many other factors have contributed to the lack of homegrown theorising. As scholars here point out, even without the Mulkiye monopoly, general educational training in analytical thinking remains under-emphasised in Turkey, and memorisation-based learning still prevails. This style rewards replication and eliminates any real need for learning alternative ways of looking at subjects. There is little investment on methodology training in Turkey, and thus training in the art of scholarship remains extremely weak. Even the leading IR departments often fail to recognise the value of teaching methodology, with some having done away with or at least questioned the value of having separate methodology courses for their graduate students. A former chair of a leading IR department connects the lack of methodology with the underachievement in theorising when he says that IR in Turkey 'never promoted the value of comparative studies, and therefore learning about other cases, comparing, producing generalisations, remained weak. We only studied our case. Without generalisation, theorising becomes impossible.' The natural outcome of this single-minded emphasis on the Turkish case has been a limiting of chances for theorising. Either the lack or poor quality of methodology training results in students/scholars skipping the crucial stage of 'pre-analysis' that must occur in theoretically-based scholarship. Clearly defining the research question, locating a gap in the theoretical and empirical literature, discussing alternative methods for analysing the question, identifying appropriate theoretical frameworks and methodological tools - all of these stages critical to both theorising and well-argued research receive only passing attention.

Many IR scholars also note that in Turkey theoretical work simply doesn't pay back - it doesn't get you media coverage or project funding and it doesn't even guarantee you a better job. Theorising is a luxury. Two professors from leading Turkish state universities both referred to the envy they felt for their European and North American colleagues, whom they believe are able to gain special professional recognition for theorising and publishing theoretical works in particular venues, whereas in Turkey they are kept overly busy with teaching (often having to supplement low pay standards by teaching extra courses at private universities) and are not recognised for serious publishing efforts. In the words of one, 'they don't slap your face if you publish, but they don't pat you on the back either'. The other speaks of his wish to 'have enough money to pay someone else to teach my courses, I would love to spend my time to produce theoretical works.' Instead, recognition, status, and money for the Turkish IR scholar is still more likely to come from writing policy pieces - these get you television spots, invitations to write newspaper columns, and opportunities for government contracts. Even though governmental funding for research in Turkey has increased significantly in recent years, experience from the 
homegrown theorising study group has shown that for theoretical based initiatives particularly in the social sciences - funding is still in short supply. This suggests the need for core funding agencies to remember that if they do not fund peripheral theorising, probably no one will.

A deeper structural problem that works against the possibility of conceptual works being produced in Turkey is the lack of established criteria for publication standards. In the West, the most prestigious journals often have a theoretical emphasis. Since publishing in them carries the promise of widespread recognition, promotion, and better employment, the effort seems worthwhile. In Turkey there remains little incentive to opt for publishing in the seemingly more difficult venues of theoretical research. True, for promotion in Turkish universities a greater numbers of points are now credited to articles published in Social Science Citation Index journals, but the overall total requirement of points remains very low, so points can easily be achieved through other routes. Among these other routes are Turkish-medium, non-theoretical journals, among which there is little in the way of agreed upon standards. When an article quickly published in a newly launched 'refereed' journal out of a newly established IR department in a new university in rural Turkey can be counted for academic promotions across the country, why struggle against huge odds to get published in International Organization or Review of International Studies?

In order to set such standards, and therefore even more critical for the long-term development of theorising from the local IR context, there is the need for a cohesive, conscious, organised, and institutionalised IR disciplinary community in Turkey. This community should have a yearly convention, a flagship journal, and a national index of acceptance criteria to evaluate Turkish publications as well as standards for quality research and training. Unfortunately, even after 50 years, such a consolidated community does not yet seem to exist.

Evidence of the Turkish IR community's lack of such cohesiveness and organisation is the fact that there have been only a handful of occasions in its history that scholars have come together to discuss the state of the discipline. Two early meetings, in 1959 and 1961, were followed thirty-five years later by a third, ${ }^{28}$ a fourth in $2001^{29}$ and the most recent in $2005 .{ }^{30}$ Except at the last of these meetings, the participants were exclusively from Ankara - reflecting the on-going division of the domestic core and periphery. More disturbing from the view of disciplinary development, is the observation made in 2005 by a senior scholar who was personally familiar with the earlier meetings, that, in all of them the challenges and questions debated remained the same: what is IR, what should we teach, and how can we build an IR discipline.' 31 Clearly little or no progress has been made on these most basic of questions, a sobering note suggesting that IR in Turkey remains at best a loosely knit, fragmented community, unable yet to build a coherent accumulation of research agendas and findings or offer suggestions for future research.

\footnotetext{
28 The Workshop on IR Teaching in Turkey, held in 1996 at Middle East Technical University, Ankara.

29 The May 2001 panel on Deconstructing and Redefining IR, held at Marmara University in Istanbul.

30 The Workshop on the Study and Education of IR in Turkey, the minutes of which were published in a special volume of the journal, Uluslararasi Iliskiler, 2:6 (Summer 2005). A large-scale meeting is also scheduled to take place in Northern Cyprus in April 2007, suggesting a greater regularity for such meetings can be expected.

31 Ersin Onulduran cited in the minutes of the 2005 workshop.
} 


\section{Core-based causes}

Turkish scholars are of course not the only source of blame for the lack of Turkish theorising. A large share must fall on the core, where training patterns, advisor/ student relationships, core prejudices, and scholarly competition all tend to push the periphery student and scholar away from engaging fully in theoretical discussions. Examples from the experiences of two Turkish scholars' may strike familiar bells with other periphery students who have studied in the core. In one case, a female IR scholar reported asking for advice on how to pursue IR-track studies in her political science department from a Turkish scholar who had lived and worked in the US for many decades. His response was, 'You might as well go right into comparative politics. We all start off in IR, and we all end up in comparative politics.' Yet another scholar who studied in Europe in the early 1990s reported experiencing the same attitude:

Core scholars are looking for people to work on their theories and prove them in new lands so that they can tell their colleagues that their ideas are being read about and applied in China or the Middle East. They aren't looking for new theoreticians. They're looking for native colonials to sell core products in new lands, whether these are new epistemological fixations or hardline methodological preferences or concrete theories. The best they do for their developing world pupils is perhaps to force them into applying their own theories. Of course, when they tell them to do this, they don't expect them to question or revise those theories with some Oriental input. The problem with this though is once the pupil adapts the advisor's theoretical identity and assumes this confirming role, it's very hard to make the jump to a critical, revisionist mode for generating new theories. Once you become the agent and franchiser of someone, it's not easy to try and produce your own product. We see McDonalds pushing aside the old age kofte (meatball) stands in Turkey in the same way.

\section{Prospects}

On the Turkish front, there are several hopeful signs that we will see greater achievements in IR theorising in the years to come. The fact that three of the handful of Turkish IR disciplinary gatherings have taken place within the last decade suggests that there are increasing efforts for community building and for coming to terms with the challenges that face the local discipline. The last gathering in particular, in 2005, was exceptional in the sense that it gathered together the domestic 'core' and 'periphery.' Though the minutes of the meetings show that core voices still remain dominant, the effort gives hope that a relatively integrated IR community can grow in Turkey before this distinctive domestic core/periphery structure becomes further consolidated. Useful ideas to this effect came during the meeting from a senior scholar and graduate of the Mulkiye, who proposed that scholars from rural Turkish universities be encouraged to teach as visiting scholars at the leading universities in the major cities, thereby allowing them to play more active roles in the community. She also suggested developing a programme to support these scholars' attendance at international conferences. ${ }^{32}$ The good news is that these ideas are already being

32 Duygu Sezer's suggestion, noted in the minutes of the Workshop on the Study and Education of IR in Turkey, p. 113. 
partially supported by government policies. The Scientific and Technological Research Council of Turkey (TUBITAK) is organising a programme to promote scholarly exchanges within Turkey, and the Higher Education Council is working to place graduate students from rural areas for training in the domestic core universities, so that they will later go back to teach in periphery institutions.

In terms of Turkish publishing venues, the 1990s witnessed an explosion in the number of think-tanks in Turkey and consequently in journals reflecting the policy priorities of these think-tanks. At the same time, major universities shied away from publishing journals. There seems however to be some signs of a shift. Though not coming directly out of a university, the new journal 'Uluslararasi Iliskiler Dergisi' (International Relations Journal) was launched by two SBF professors, and appears to be an exception, promoting the publication of theoretical research. Another hopeful sign of community building and progress was the holding in 2006 of the 5th annual international IR conference at Middle East Technical University - a conference that tries each year to combine theory, policy, and area studies.

\section{Homegrown theorising and becoming a community}

If these trends continue, and if able and interested scholars begin producing increasing examples of successful homegrown theorising efforts, these activities may become the driving energy behind a new image and substance for the IR community in Turkey. IR in Turkey seems still mired in questions about what the discipline should be doing. While IR communities in the West have not necessarily resolved their existential debates about 'what is IR?', they have in many cases still been able to go beyond these basic questions by building up long-term research agendas and research paradigms often based on 'great debates' - for example realism versus idealism. These Western communities have become communities through hands-on practice of IR, not through meta-cognitive debates of the question. The growth of homegrown theory in IR in Turkey can play a similar leading role in defining such debates, from epistemological and methodological questions through the formation of formal IR theories. It is surprising for example, that given Turkey's critical relations with the European Union, IR in Turkey over the years has not taken a leading role in debating and contributing to integration theories.

Turkish theorists can also take a leading role in helping fight the IR community's fears of infiltration of poor quality scholarship, of an epidemic of 'conspiracy theorising' (attractive to the masses in its simplicity and parsimony but empty of methodology) and an overlap between journalism and IR. It has been pointed out that these challenges to the discipline are best met by standing firmly behind vigorous theoretical and methodological work with global standards. ${ }^{33}$ Turkey's theoreticallyinclined IR scholars should draw on their own training, produce quality examples of scholarship, and make clear the differences between scholarly research and speculation.

${ }^{33}$ Gun Kut refers in particular to the role of methodology as the only 'weapon' against the inflation of this 'conspiracy theorising', p. 51. For similar suggestions see the comments of Beril Dedeoglu (p. 49), in response to the overwhelming concern expressed by the workshop attendees about the difficulty of distinguishing 'good' quality IR from 'bad' quality IR - or simply 'non-IR'. 
Of course, such noble efforts can not be achieved unless the quality of the research supports it. 'Theorising' will have to come to mean more than just a balancing tool, and simply claiming to do theory can no longer be enough to provide ammunition for self-identification and superiority. The burden of going beyond the current image, misrepresentations and misuse of theory lies with those who claim to be theorists. Turkish scholars have to recognise that theory does not mean better, but in fact demands the close support and cooperation with case studies, area studies, and policy studies. This attitude must be transferred in the classroom. Teaching IR theory both in the US and in Turkey has shown us that if you fail to communicate to students the use of theory for their needs and contexts, you immediately lose the good will of a large portion, and may even encounter resistance from those heading towards government work or area studies. The Turkish IR theory classroom must be the frontline in putting a halt to the local disciplinary community's domestic coreperiphery structure before it becomes consolidated in labels of 'theorists' and 'others'.

\section{Homegrown theorising and core-periphery IR disciplinary relations}

The question remains as to what such positive developments in local IR theorising might mean for future relations between the Turkish and core IR communities. Turkish IR scholars currently complain that their attempts to have their voices heard in core IR theoretical discussions go unheard. Their scholarly efforts, when recognised by the core, seem to hold importance only as far as they represent a national view (for example a Turkish perspective on the Iraqi situation, or a Turkish perspective on energy politics in Eurasia). As one senior IR scholar noted several years ago:

What happens is that you become good for area studies. So I do get to teach at good universities in the U.S. and Europe, but it's all on Middle Eastern politics. And when you get invited to conferences, it's not for the contributions that you might make to theory or conceptual thinking, but more to sort of case studies, or area studies, or sort of empirical descriptive analyses, and that, to be honest, hurts. That hurts.

His dismay extended beyond the personal affront however, to concern over the resulting construction of disciplinary knowledge in such a compartmentalised environment:

What I have noticed over the last few years is that I find colleagues in the West slipping into generalizations, and theorizing that is really remote from what one might consider as the reality out there. And that really is at times almost scary. What happens is that maybe the lack of very in-depth knowledge of cases or areas by and large leaves this group ignorant of all this, and then they get involved in an exercise that reinforces each other. And when, say, someone like me comes in and I throw a question at them, it really generates a moment of silence, and we can sense that the whole thing is thrown off balance. There is a moment of insecurity there, but it's only a moment and then they push on.

In such an environment, what might an increase in home-grown Turkish - or other peripheral-theorising mean for local-core disciplinary relations? The potential is a positive one, that may imply a re-distribution of epistemological advantages and disadvantages. Rather than periphery scholars attempting to participate as outsiders in core theoretical discussions by trying to explore the same questions - and possibly 
being viewed therefore as either superfluous to the discussion or worse yet as trying to 'trip up' core theorists with examples from local experiences - periphery IR scholars may be better off participating as newcomer theorists, with their own set of questions, stemming from different contextual conditions.

In the natural tendency to create hierarchies, homegrown theorising out of the periphery would probably in the short run take second seat to theorising out of the core. On the other hand, such theorising would recognise the politics of difference ${ }^{34}$ of periphery theorists, and allow for the possibility of discovering what, for example, a Turkish version of IR theorising might be like. The alternative seems to be a seemingly futile quest for periphery scholars, the ultimate goal of which is the dubious one of assimilation into one core theory community, or another. ${ }^{35}$ Periphery scholars engaging in homegrown theorising would trade the loss of some equality (which never really existed anyway) for a boost to distinctiveness, which may be the only route to another kind of equality. It seems a worthwhile exchange. An increase in homegrown theorising out of the periphery will naturally spawn greater coreperiphery dialogue on theory in IR, and help to reduce the negative experiences of pigeon-holed periphery scholars. It will ultimately improve IR theorising overall by enriching its sources and perspectives in a world of global politics, in which no region and no perspective can be ignored.

${ }^{34}$ A reference to Charles Taylor's Multiculturalism and the 'Politics of Recognition': An Essay, which struggles with the inherent contradiction between a politics of equal dignity, in which we must apply an identical standard of rights and immunities to all, and a politics of difference, in which each individual or group's unique identity is recognised (Princeton, NJ: Princeton University Press, 1992).

35 One wonders whether theorising in the periphery might not turn out to be the next battlefield for trans-Atlantic paradigm battles, as countering schools of thought from North America and Europe seek to gain prominence in newly emerging arenas. It could be argued, for example, that a work like Callahan's discussion of how IR theory is being built up in the Chinese context, is critical of peripheral embracing of 'rationalist' views on theorising not due to concerns over incompatibility or inappropriateness of the perspective for that context, but rather due to concerns that American views on social science seem to be gaining prominence there. Callahan, 'China and the Globalisation of IR Theory'. 